\title{
Análise quantitativa dos dados para um protótipo de dicionário semibilíngue de expressões idiomáticas
}

DOI: http://dx.doi.org/10.21165/el.v49i1.2550

Natália Gabrieli dos Santos Fagundes Euzébio

\section{Resumo}

Considerando as expressões idiomáticas como estruturas léxicas complexas, polilexicais, de sentido figurado e cristalizadas pela tradição cultural de um povo (XATARA, 1998), este trabalho tem como objetivo apresentar uma amostra das expressões levantadas até o momento e a análise quantitativa parcial dos dados em língua portuguesa coletados em uma pesquisa de mestrado, ainda em desenvolvimento, que visa à elaboração de um protótipo de dicionário semibilíngue de expressões idiomáticas, sob um olhar Fraseodidático. Tem-se como base os princípios teóricos da Fraseologia oferecidos por Tristá Perez (1988) e Montoro del Arco (2006), da Fraseografia por Olímpio de Oliveira Silva (2007), da Lexicologia por Biderman (2001) e da Lexicografia por Haensch (1982) e Porto Dapena (2002). O desenvolvimento da pesquisa realiza-se sob o ponto de vista metodológico da Linguística de Corpus (SARDINHA, 2000; TAGNIN, 2011), por meio da elaboração de um corpus de textos jornalísticos do caderno de esporte, jornal digital Estadão e pretende a elaboração de um material que auxilie professores e aprendizes de nível inicial da língua espanhola.

Palavras-chave: expressões idiomáticas; dicionários; fraseologia; fraseografia; fraseodidática.

1 Universidade Federal de Mato Grosso do Sul (UFMS), Campo Grande, Mato Grosso do Sul, Brasil; nataliafagundes2014@gmail.com; https://orcid.org/0000-0001-7749-8773 


\section{Prototipo de diccionario semibilíngüe de expresiones idiomáticas portugués - español: un análisis cuantitativo de los datos}

\section{Resumen}

Considerando las expresiones idiomáticas como estructuras léxicas complejas, polilexicales, figurativas y cristalizadas por la tradición cultural de un pueblo (XATARA, 1998). Este artículo tiene como objetivo presentar una muestra de las expresiones recogidas hasta el momento y un análisis cuantitativo parcial de los datos en lengua portuguesa recopilados en una investigación de maestría, aún en desarrollo, la cual apunta la elaboración de un prototipo de diccionario semibilíngüe de expresiones idiomáticas, bajo una mirada Fraseodidáctica. Se basa en los principios teóricos de la Fraseología ofrecidos por TristáPerez (1988) y Montoro del Arco (2006), de la Fraseografía por Olímpio de Oliveira Silva (2007), de la Lexicología por Biderman (2001) y de la Lexicografía por Haensch (1982) y Porto Dapena (2002). Desde el punto de vista metodológico de la Lingüística de Corpus (SARDINHA, 2000; TAGNIN, 2011), ocurrirá, a través de la elaboración de un corpus de textos periodísticos de los cuadernos deportivos, versión digital del "Estadão" y pretende desarrollar un material que ayude a los profesores y aprendices del nivel inicial del español.

Palabras-clave: Expresiones Idiomáticas; Diccionarios; Fraseología; Fraseografía; Fraseodidáctica.

\section{Introdução}

Considerando que a língua possui um caráter dinâmico e que funciona como a identidade cultural de um povo, admitimos que "qualquer sistema léxico é a somatória de toda a experiência acumulada de uma sociedade e do acervo da sua cultura através das ideias" (BIDERMAN, 2001, p. 179). Desde o início da Linguística Moderna, com Saussure, as unidades complexas da língua são percebidas, no entanto, somente com o crescimento das pesquisas na área da Fraseologia tais estruturas passam a ser estudadas com maior atenção.

Por sua natureza dinâmica, a língua permite que seus usuários possam utilizá-la da maneira que melhor se adéque às condições comunicativas, no entanto, apesar de sua recursividade, dispõe de restrições nas suas combinações. Essas restrições se tornam mais evidentes quando adentramos o campo da Fraseologia, pois adentramos um campo da língua que até mesmo para um falante de língua materna não se evidencia de maneira inteiramente simples, sobretudo, se considerarmos as variações linguísticas e culturais do país em que essa língua é falada. 
No Brasil, apesar do recente crescimento no interesse pela área da Fraseologia, é notável o aumento das publicações de dissertações e teses de mestrado e doutorado que pesquisam sobre as $\mathrm{El}$, contudo, no que diz respeito à elaboração de dicionários monolíngues, semibilíngues e bilíngues, contudo, ainda são poucos os trabalhos que tratam da elaboração de obras lexicográficas voltadas para o ensino.

Objeto de estudo desta pesquisa, as expressões idiomáticas são formadas por estruturas léxicas localizadas no nível oracional da língua, plurilexicais, de sentido figurado e cristalizadas pela tradição cultural de uma comunidade linguística (XATARA, 1998). Apesar de representarem grande parte do léxico, os fraseologismos não recebem nas obras lexicográficas o tratamento léxico necessário e, em grande parte dos dicionários, não encontramos sequer a classificação dos diferentes tipos de unidade fraseológica (colocação, provérbios, expressão idiomática, dentre outros).

Se, pensarmos, pois, no uso recorrente das El tanto na modalidade oral da língua, quanto na modalidade escrita e, consequentemente, na importância dessas estruturas dentro do ensino de língua materna, bem como no ensino de língua estrangeira, é perceptível a carência de obras lexicográficas que explorem o tema com maior afınco e possibilitem aos aprendizes um acesso amplo ao sentido global das El, como também, a apresentação de sua contextualização e dos seus equivalentes em uma segunda língua.

Neste cenário, este trabalho tem como objetivos:

1) apresentar uma amostra parcial dos dados em língua portuguesa de uma pesquisa de mestrado em desenvolvimento, que visa à elaboração de um protótipo de dicionário semibilíngue de El.

2) apresentar os resultados parciais de uma análise quantitativa dos candidatos a El coletados até o presente momento.

O desenvolvimento da proposta de pesquisa tem como princípios teóricos: a) os estudos da Fraseologia no que se refere às noções de El de Tristá Pérez (1988), Xatara (1998) e Montoro del Arco (2006); b) os conceitos-base da Fraseografia propostos por Oímpio de Oliveira Silva (2007); c) na compreensão da Lexicologia e do conceito de léxico por Biderman (2001); e d) as concepções empreendidas no âmbito da Lexicografia por Haensch (1982) e Porto Dapena (2002). De cunho qualitativo, descritivo e analítico, o trabalho ainda propõe um diálogo metodológico com a Linguística de Corpus, sob o viés adotado por Sardinha (2000) e Tagnin (2011). 


\title{
Delineando os caminhos do léxico
}

A Lexicologia é a disciplina responsável pelo estudo das unidades lexicais de uma ou várias línguas e em todos os seus aspectos, ou seja, que se encarrega do estudo da palavra, tomando como objetivo a descrição do léxico. Pensando, pois, no léxico enquanto um repertório de palavras, assumimos, em concordância com Biderman (2001, p. 178), que:

\begin{abstract}
O léxico de qualquer língua constitui um vasto universo de limites imprecisos e indefinidos. Abrange todo o universo conceptual dessa língua. Qualquer sistema léxico é a somatória de toda experiência acumulada de uma sociedade e do acervo de sua cultura através das idades. [...] Nesse processo em desenvolvimento, o léxico se expande, se altera, e, às vezes, se contrai. As mudanças sociais e culturais acarretam alterações nos usos vocabulares; daí resulta que unidades ou setores completos do léxico podem ser marginalizados, entrar em desuso e vir a desaparecer. Inversamente, porém, podem ser ressuscitados termos que voltam à circulação, geralmente com novas conotações. Enfim, novos vocábulos, ou novas significações de vocábulos já existentes, surgem para enriquecer o léxico.
\end{abstract}

Como evidenciado na seção anterior, a língua é um sistema dinâmico que está em constante movimento e é por meio do léxico que não só nomeamos o mundo, mas também, o compreendemos, haja vista que "é a partir da palavra que as entidades da realidade podem ser nomeadas e identificadas. A denominação dessas realidades cria um universo significativo revelado pela linguagem." (BIDERMAN, 1998, p. 88).

Em razão da diversidade do léxico e das necessidades de comunicação, surgem os primeiros trabalhos de caráter lexicográfico. Inicialmente, na Grécia, produziam-se glossários em prol da melhor comunicação entre os cidadãos, já que passavam por uma fase de bilinguismo e, com a estruturação das sociedades medievais, as línguas vulgares se sobrepunham ao latim. É somente a partir dos séculos XVI e XVII que se torna possível a elaboração de dicionários, iniciando ao que temos hoje como Lexicografia.

Com o nascimento dos primeiros repertórios lexicográficos surge a necessidade de uma organização estruturada do léxico, por meio dos glossários e dicionários, fator que mais tarde permite a evidenciação do caráter didático do dicionário, como afirma Hernández (1989, p. 32 apud PEREIRA, 2018, p. 27):

A consideração do dicionário como uma obra de caráter didático é um dos princípios mais comumente difundidos pela maioria dos estudiosos repetido em grande parte de seus trabalhos. Esta capacidade didática é inerente ao dicionário porque sua missão é a de proporcionar informação ao usuário com o objetivo de facilitar a comunicação linguística. 
Em 1982, Werner propõe a relação de duas vertentes no âmbito lexicográfico, a Lexicografia e a teoria da Lexicografia. Pereira (2018, p. 31) explica que o autor entende que "a primeira seria utilizada para todo o domínio da descrição léxica que se concentre no estudo e descrição dos monemas e simonemas dos discursos individuais e dos sistemas linguísticos coletivos", enquanto a segunda seria a responsável por "designar a metodologia científica da Lexicografia".

A partir de então, começam a surgir obras lexicográficas com finalidades distintas, com base na necessidade social dos falantes, nos mais variados âmbitos. Nesse contexto, surge a Lexicografia Pedagógica ou Lexicografia Didática, "ciência que estuda [...] as relações entre os dicionários e os destinatários", bem como "a crítica, a elaboração e o uso de dicionários escolares" (PEREIRA, 2018, p. 32).

No final do século XX, na década de 80, no âmbito pedagógico, Hernández (1989 apud PEREIRA, 2018, p. 32) propõe uma definição que abarca tanto a vertente teórica, quanto a vertente prática da Lexicografia, considerando-a enquanto domínio da Linguística Aplicada.

Para o autor, a Lexicografia seria "a disciplina da linguística aplicada que se encarrega dos problemas teóricos e práticos que apresenta a elaboração de dicionários" (HERNÁNDEZ, 1989, p. 8 apud PEREIRA, 2018, p. 32). Nessa perspectiva, o dicionário passa a ser objeto de estudo da Lexicografia, ao mesmo passo que o pesquisador o toma como objeto de análise.

No domínio da Lexicografia Pedagógica cabe o estudo e a produção de dicionários voltados para aprendizado de línguas, seja de língua materna, seja de língua estrangeira, servindo como um instrumento de ensino e aprendizagem para professores e alunos. Essa área de estudo busca refletir tanto sobre a parte teórica, relacionada ao estudo dos dicionários pedagógicos, quanto à parte prática, relacionada à produção dessas obras.

A produção de obras lexicográficas pedagógicas permite ao professor utilizar o dicionário enquanto uma ferramenta pedagógica contribuindo, assim, para o desenvolvimento das competências comunicacionais do aprendiz em diferentes contextos. É importante ressaltar que nem toda obra lexicográfica deve ser classificada ou denominada como pedagógica ou didática, pois nem todo dicionário é disposto, estruturado de forma didática.

\section{A Fraseologia e a Fraseografia}

Segundo Tristá Pérez (1998), a Fraseologia foi fundada e instituída como disciplina pelo linguista francês Charles Bally e, em linhas gerais, podemos dizer que, afiliada às Ciências do Léxico, tem como objetivo definir, descrever e caracterizar as unidades fraseológicas. 
Vale ressaltar que, apesar de existirem estudiosos que abordam a Fraseologia na condição de subárea da Lexicografia, neste trabalho, reclamamos a viabilidade de tratála, como bem explicita Monteiro-Plantin (2017, p. 12), uma "disciplina independente, cujo objetivo de estudo está relacionado a todos os níveis de análise linguística, do fonético ao discursivo-pragmático".

Os estudos fraseológicos se organizam a partir de duas abordagens distintas: a concepção estreita e a concepção ampla. A primeira considera como unidades fraseológicas todas as combinações fixas do léxico que, em sua estrutura, equivalham a um sintagma. Nesta pesquisa, porquanto, adotamos a segunda concepção que considera como fraseologismo "todas as unidades que manifestem pluriverbalidade e algum grau de cristalização" (MONTORO DEL ARCO, 2006, p. 76), ou seja, colocações, provérbios, expressões idiomáticas, dentre outras.

Responsável pela "elaboração dos preceitos teóricos que determinam a produção de dicionários fraseológicos" (OLÍMPIO DE OLIVEIRA SILVA. 2007, p. 21, tradução nossa²), a Fraseografia surgiu há mais de duas décadas na linguística soviética e se delineia a partir da relação existente entre a Fraseologia e a Lexicografia.

Por isso é importante que os conceitos abordados pela Fraseologia estejam claros, para que a Fraseografia possa destinar o tratamento lexicográfico adequado para as unidades fraseológicas. Um dos problemas que caracterizam a marginalização das unidades fraseológicas refere-seao descuido quehouve com otratamento metalexicográfico dessas unidades, sobretudo nos dicionários, devido ao atraso das descrições fraseológicas.

Alguns autores, como Carneado Moré e Tristá (1986), apontam que a Fraseografia se ocupa apenas do espaço da produção e análise crítica de dicionários fraseológicos, no entanto, em consonância com os estudos de Olímpio de Oliveira Silva (2006, p. 27, tradução nossa ${ }^{3}$ ), depreendemos a Fraseografia como:

[...] uma disciplina linguística que se ocupa, por uma parte, dos princípios teóricos e práticos que regem a inclusão da fraseologia em compilações léxicas (dicionários, léxicos, vocabulários, glossários, concordâncias, etc.), tanto restritas,

2 No original: "[...] se ocupa de la elaboración de los preceptos teóricos y prácticos que determinan la producción de diccionarios fraseológicos.".

3 No original: "La fraseografía es una disciplina lingüística que se ocupa, por una parte, de los principios teóricos y prácticos que rigen la inclusión de la fraseología en compilaciones 1 éxicas (diccionarios, léxicos, vocabularios, glosarios, concordancias, etc.), tanto restringidas como generales y, por otra, del estudio crítico y descriptivo de estas compilaciones, en lo que al tratamiento de la fraseología se refiere, lo que significa decir que el ámbito de interés de la fraseografia comprende desde la presentación tipográfica seguida en la obra hasta la adecuación a los usuarios. 
quanto gerais e, por outra, do estudo crítico e descritivo dessas compilações, no que se refere ao tratamento da fraseologia, o que significa dizer que o âmbito de interesse da Fraseografia compreende desde a apresentação tipográfica seguida na obra até a adequação aos usuários.

Assim como a Fraseologia, a Fraseografia também apresenta duas interfaces, uma com enfoque nos estudos da história, descrição, crítica, pesquisas e da teoria fraseográfica, chamada de Fraseografia Teórica ou Metafraseografia, e uma segunda, conhecida por Fraseografia Prática, que se dedica ao tratamento e inclusão das unidades fraseológicas em dicionários gerais ou específicos, bem como seus princípios metodológicos.

\section{A pesquisa}

Conforme já referenciado no tópico de introdução, este trabalho tem como objetivo realizar uma análise quantitativa parcial de uma amostra dos dados coletados, em uma pesquisa de mestrado em andamento. Portanto, para que haja um entendimento dos dados analisados, faz-se necessário o conhecimento de alguns pontos da pesquisa, como: a) seu objetivo geral; e b) seu caráter metodológico, no que tange à constituição e elaboração do corpus.

A pesquisa de mestrado, da qual deriva este trabalho, tem como objetivo geral a proposta de elaboração de um protótipo de dicionário semibilíngue de expressões idiomáticas, a partir da construção de um corpus de textos jornalísticos, com enfoque na relação entre a língua portuguesa (vertente brasileira), como língua materna (LM), e a língua espanhola (vertente peninsular), como língua estrangeira (LE), sob as bases teórico-metodológicas advindas das perspectivas da Fraseologia, Fraseografia, Lexicografia e Lexicografia Pedagógica.

Enquanto objetivos específicos, ressaltamos dois que aqui nos interessam e que compreendem: i) a ampliação do corpus, levantamento, análise e verificação da frequência de uso das expressões idiomáticas em textos jornalísticos, mais especificamente nos cadernos de esportes, da versão digital do jornal paulista Estadão, bem como a análise dos contextos de uso apresentados no corpus, para a construção do sentido global das expressões idiomáticas; e ii) levantamento e análise dos dados, verificação da incidência de uso das expressões idiomáticas, bem como seus contextos de uso.

Tendo por meta a realização dos objetivos gerais e específicos, e com base nos princípios metodológicos da Linguística de Corpus (SARDINHA, 2000; TAGNIN, 2011), a pesquisa foi dividida em etapas e, para este recorte, cabe explicitar como se deu a elaboração e armazenamento do corpus. Esta etapa, por sua vez, compreende alguns passos que, a seguir, serão apresentados por tópicos, em conformidade, com sua ordem de execução: 


\section{Elaboração do corpus e computadorização dos dados}

- Armazenamento do corpus em formato txt;

- Análise do corpus.

- Coleta das unidades candidatas a expressão idiomática;

- Construção da base de dados.

Antes de descrever a elaboração do corpus, vale ressaltar que a proposta deste trabalho surgiu a partir da realização de uma pesquisa anterior em um grupo de estudos da área da Fraseologia, durante o programa de Iniciação Científica. Propõem-se, portanto, a ampliação desse corpus já desenvolvido anteriormente.

Os dados foram coletados nos cadernos da seção de Esportes do jornal paulista Estadão, dentro do espaço temporal de 2014 a 2019, sendo que, de cada ano, compreendemos um período de dois meses, semanalmente, de segunda-feira a sexta-feira. Os textos coletados são armazenados em pastas dispostas nos documentos do computador da pesquisadora, bem como em pendrives e no Google One Drive ${ }^{4}$, conforme os meses, dias e as páginas.

Após a coleta, os dados são transformados do formato de texto PDF para o formato TXT ${ }^{5}$, já que este possibilita a mobilidade em ferramentas computacionais específicas para análise do corpus. Em seguida, as expressões são dispostas em uma tabela, projetada pelo programa Microsoft Excel/, que permite uma boa visualização e mobilidade dos dados. Esta etapa tem como objetivo estabelecer pontos que tracem o perfil da El e seu contexto de uso. Após o preenchimento da tabela, a base de dados está pronta e pode ser utilizada na elaboração dos verbetes do protótipo.

\section{Base de dados}

Para este artigo, utilizar-se-á um recorte dos dados, referentes ao ano de 2015, meses de setembro e outubro.

4 A escolha de ter o corpus disposto em uma "nuvem" on-line permite uma maior segurança dos dados.

5 O formato "txt" consiste em uma extensão de arquivos de textos com poucas marcas de formatação, o que permite que o texto seja empregado em editores e programas mais simples.

6 Editor de planilhas produzido pela Microsoft para computadores que utilizam o sistema operacional Microsoft Windows. 
Tabela 1. Relação de quantidades que compõem a base de dados a ser analisada

\begin{tabular}{l|l|l}
\hline Total & Setembro & Outubro \\
\hline Dias de coleta & 22 & 21 \\
\hline Páginas de textos armazenadas & 52 & 66 \\
\hline El levantadas por mês & 107 & 103 \\
\hline El coletadas & 210 & \\
\hline
\end{tabular}

Fonte: Elaboração própria

\section{Análise dos dados}

Serão realizadas duas análises a partir da amostra de dados coletadas, a primeira delas é referente à classificação das expressões idiomáticas por nome: a) de animais; b) de partes do corpo humano; e c) de alimentos e bebidas. A segunda análise refere-se à localização dessas expressões tanto nos textos (título, subtítulo, legenda de fotos, corpo do texto, etc.), quanto nas subseções do caderno (futebol, natação, campeonato brasileiro, etc.).

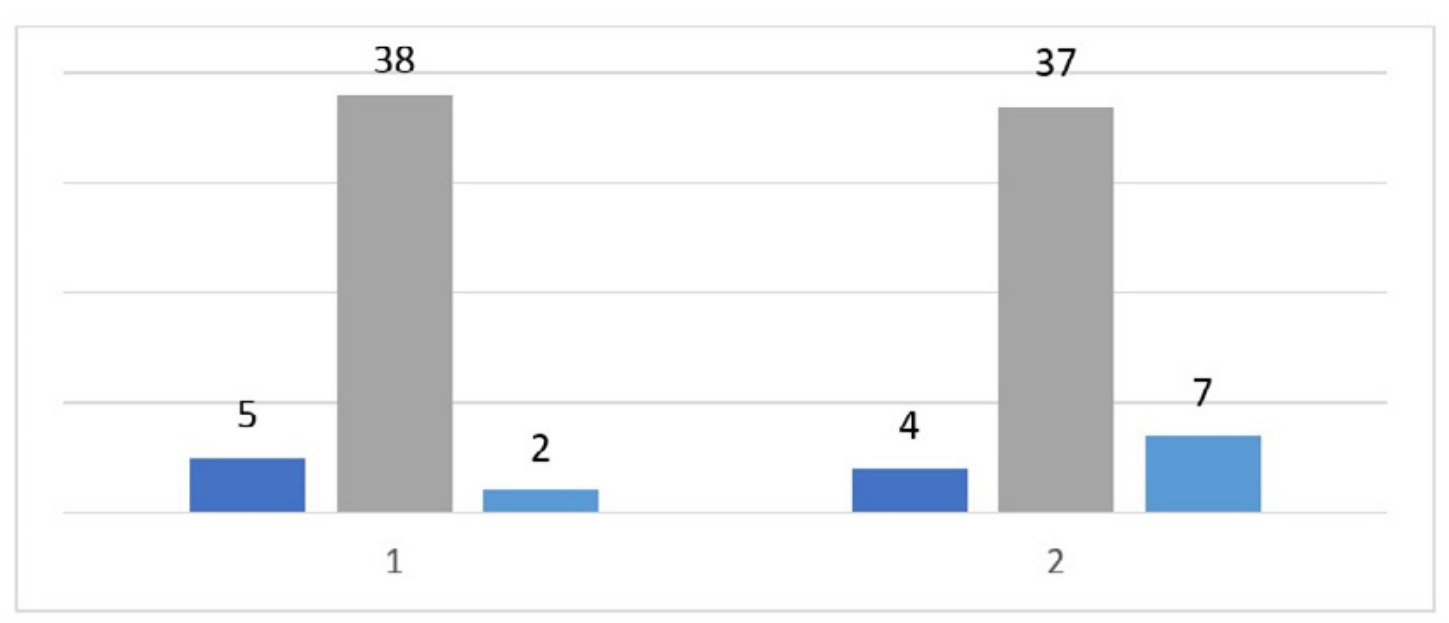

\section{Animais Partes do Corpo Humano Alimentos e Bebidas}

Gráfico 1. Análise quantitativa de expressões idiomáticas por nome

Fonte: Elaboração própria 
Depreende-se, a partir dos dados expressos no gráfico, que nos dois meses há uma grande recorrência de expressões idiomáticas que têm na sua constituição o nome de alguma parte do corpo humano, sendo no mês de setembro (1) 38 e no mês de outubro (2) 37 expressões idiomáticas. Já as expressões idiomáticas com nomes de animais e de alimentos e bebidas têm uma menor recorrência no corpus; nos dois meses foi encontrado um total de 10 expressões referentes a nome de animais e nove referentes a nome de alimentos ou bebidas.

Com relação ao número de repetições, as expressões de maior recorrência são: abrir mão (17 ocorrências no corpus) e pagar o pato (cinco ocorrências no corpus). Os nomes de animais encontrados no corpus, além do já citado, são: leão (matar um leão por dia, despertar o leão ferido); porco (espírito de porco); zebra (espantar a zebra); e burro (doer pra burro).

A variedade de nomes de partes do corpo humano é bem maior, partes como mão, pé e cabeça aparecem 47 vezes. O detalhamento desses dados engloba as seguintes expressões: mão (abrir mão, ficar com o coração na mão, mão de alface, estar com a faca e o queijo nas mãos); pé (manter os pés no chão, pés no chão, tirar o pé do acelerador, começar com pé direito, jurar de pés juntos); cabeça (pedir a cabeça, passar um filme na cabeça, ter a cabeça a prêmio, colocar a cabeça no lugar, levantar a cabeça).

Além dessas de maior recorrência também aparecem no corpus: traseiro (cinco ocorrências), fundilhos (uma ocorrência), bunda (uma ocorrência), boca (quatro ocorrências), bico (relativo ao uso popular para denominar "boca" - uma ocorrência), cara, pescoço, olhos e costas (duas ocorrências), orelha, ouvido, barriga, pele, nariz, papo, coração e calcanhar (uma ocorrência).

Já em relação às expressões idiomáticas com nome de alimento ou bebidas, não há repetições, contudo, a bebida "água" é a de maior incidência, aparecendo em 4 das 8 ocorrências encontradas (Ir por água abaixo, se transformar da água pro vinho, jogar um balde de água fria e estar em águas calmas). As outras expressões presentes no corpus são: estar com a faca e o queijo nas mãos, chato pra chuchu, colher de chá, mão de alface.

No que diz respeito à localização dessas expressões no texto, pode-se dizer que: 
Tabela 2. Localização das expressões idiomáticas no texto

\begin{tabular}{c|c}
\hline Localização & Quantidade de expressões idiomáticas por mês \\
\hline Corpo do Texto & $\begin{array}{c}\text { Setembro: } 102 \\
\text { Outubro: } 98\end{array}$ \\
\hline Legenda de Foto & Outubro: 1 \\
\hline Título & Setembro: 5 \\
Outubro: 4
\end{tabular}

Fonte: Elaboração própria

No que se refere à localização das expressões idiomáticas nas subseções do jornal, pode-se dizer que as de maior expressividade, com maior recorrência são: Colunas (82 expressões); Campeonato Brasileiro (40 expressões), Copa Brasil (12 expressões), Corrupção (11 expressões), Eliminatórias (nove expressões) e Futebol (11 expressões).

\section{Resultados porcentuais}

De acordo com as análises realizadas, pode-se depreender, pensando na recorrência dessas expressões, que em relação ao percentual total: 35,7\% das expressões possuem em sua composição nome de partes do corpo humano, 4,7\% possuem em sua composição nome de animais e 4,2\% possuem em sua composição nome de alimentos. Em relação a sua localização no texto, 95,7\% encontram-se no corpo do texto dos cadernos de Esportes, 39,04\% localizam-se na subseção de Colunas e 19,04\% localizam-se na subseção do Campeonato Brasileiro.

\section{Breves conclusões}

Por meio da elaboração de uma base de dados de expressões idiomáticas e das análises realizadas neste trabalho, verifica-se que há um alto índice de recorrência de expressões idiomáticas nos textos de cunho jornalístico esportivo. Corroborando, portanto, com a tese de que as expressões são recorrentemente utilizadas e não somente nos discursos informais, mas também, em contextos mais formais da língua escrita.

Diante da análise do corpus e da recorrência das expressões, percebemos a necessidade da elaboração de obras lexicográficas que apresentem um tratamento linguístico adequado para as unidades fraseológicas. Tanto no ensino regular quanto em cursos 
de línguas a aprendizagem do vocabulário acaba restringindo-se na maioria das vezes apenas às lexias simples e compostas; em algumas unidades, os materiais didáticos apresentam as unidades fraseológicas de maneira breve, como uma curiosidade.

Reclamamos, no entanto, a necessidade de obras lexicográficas voltadas para o ensino que deem suporte aos professores e alunos, por isso a ideia de um dicionário semibilíngue que permita ao aprendiz verificar as expressões idiomáticas em sua língua materna, entendendo o seu sentido global, suas remissivas e sua aplicação em um contexto de uso, propiciando, assim, um contato não apenas com os equivalentes, de maneira solta, mas estabelecendo no universo do aluno situações reais de uso dessas expressões, para somente, então, entrar em contato com a expressão em uma segunda língua, lembrando que este tipo de obra pode ser utilizada tanto no ensino de língua materna, quanto no ensino de língua estrangeira.

Haja vista, o dicionário engloba desde as funções sociais e pragmáticas até o caráter de expressão cultural e ideológica, logo, cabe a ele tanto dar sentido às sociedades como, consequentemente, projetar suas culturas (COLLINOT; MAZIÉRE, 1997, apud KRIEGER, 2017).

É importante ressaltar que, nos estudos do léxico, a problemática inicia-se com a terminologia do seu próprio objeto, a palavra, e se estende aos mais variados conceitos, tomando um rigor maior diante das irregularidades da língua. Tal constatação reforça a necessidade de refletir a respeito da maneira como as unidades fraseológicas enquadramse sob as bases teórico-metodológicas da Lexicologia, da Lexicografia e da Fraseografia, embora os estudos desta última ainda estejam em desenvolvimento, sobretudo no Brasil.

\section{REFERÊNCIAS}

BIDERMAN, M. T. C. Teoria lingüística: teoria lexical e lingüística computacional. São Paulo: Martins Fontes, 2001.

BIDERMAN, M. T. C. Conceito linguístico de palavra. In: BASÍLIO, M. (org.). Palavra. Rio de Janeiro: Vozes, 1999. p. 81-97.

CARNEADO MORÉ, Z.; TRISTÁ, A. M. Estúdios de fraseologia. La Habana: Academia de Ciências de Cuba, 1986.

HAENSCH, G. et al. La lexicografía: de la lingüística teórica a la lexicografía práctica. Madrid: Gredos, 1982. 
KRIEGER, M. G. O dicionário de língua como potencial instrumento didático. In: ISQUERDO, A. N.; ALVES, I. M. (org.). As ciências do léxico: lexicologia, lexicografia e terminologia. Campo Grande: Ed. UFMS; São Paulo: Humanitas, 2017.

MONTEIRO-PLANTIN, R. S. Fraseologia e Paremiologia: para que ensinar, se todo mundo sabe? ReVEL, v. 15, n. 29, p. 1-16, 2017. Disponível em: http://www.revel.inf.br/ files/7e02a7f4cb22a2e4935d77ae89882e69.pdf. Acesso em: 05 abr. 2018.

MONTORO DEL ARCO, E. T. Clasificaciones de las UFs: el lugar de las locuciones. In: MONTORO DEL ARCO, E. T. Teoría fraseológica de las locuciones particulares. Las locuciones prepositivas, conjuntivas y marcadoras del español. Frankfurt am Main: Peter Lang, 2006.

OLÍMPIO DE OLIVEIRA SILVA, M. E. Fraseografía teórica y práctica. Frankfurt am Main: Peter Lang, 2007.

PEREIRA, R. R. O dicionário pedagógico e a homonímia: em busca de parâmetros didáticos. 2018. Tese (Doutorado em Linguística e Língua Portuguesa) - Faculdade de Ciências e Letras, Universidade Estadual Paulista "Júlio de Mesquita Filho", Araraquara, 2018.

PORTO DAPENA, J.-Á. Manual de técnica lexicográfica. Madrid: Arco/Libros, 2002.

SARDINHA, T. B. Lingüística de Corpus: histórico e problemática. D.E.L.T.A., v. 16, n. 2 , p. 323-367, 2000. Disponível em: http://www.scielo.br/pdf/delta/v16n2/a05v16n2.pdf. Acesso em: 07 fev. 2016.

TAGNIN, S. E. O. Linguística de corpus e Fraseologia: uma feita para a outra. In: ALVAREZ, M. L. O.; UNTERNBÄUMEN, E. H. (org.). Uma (re)visão da teoria e da pesquisa fraseológicas. Campinas: Pontes, 2011. p. 277-302.

TRISTÁ PEREZ, A. M. Fraseología y contexto. Habana: Editorial de Ciencias Sociales, 1988.

XATARA, C. M. O campo minado das expressões idiomáticas. Alfa, São Paulo, 42 (n. esp.), p. 147-159, 1998.

XATARA, C. M. A tradução para o português de expressões idiomáticas em francês. 1998. Tese (Doutorado em Linguística e Língua Portuguesa) - Faculdade de Ciências e Letras, Universidade Estadual Paulista "Júlio de Mesquita Filho", Araraquara, 1998. 